\title{
The Challenges Facing Female English Language Teachers in Secondary Schools in Jordan
}

\author{
Khloud Al-Bdeerat ${ }^{1}$, Basil Alqarraleh ${ }^{2}$, \\ Abdel Rahman M. Altakhaineh ${ }^{3}$ \\ ${ }^{1}$ Khadeja Bint Khwaylid School, Al-Karak, Jordan \\ ${ }^{2} \mathrm{Al}$ Ain University, Abu Dhabi, UAE \\ ${ }^{3}$ The University of Jordan, Amman, Jordan
}

Correspondence concerning this article should be addressed to Abdel Rahman M. Altakhaineh, The University of Jordan, Amman, 11942, Jordan. E-mail: tkabd@yahoo.com

\begin{abstract}
This study aimed to identify the obstacles facing female secondary teachers of English in AlQaser Directorate of Education in Al-Karak, Jordan. For the purpose of the study, a quantitative approach was adopted. The sample was randomly selected and included 170 female English language teachers. A questionnaire consisting of 29 items covering five domains was administered and 150 questionnaires were returned. The results showed that these teachers faced many academic challenges and obstacles in various domains, such as in the student, community, and parent domains, as well as teacher skills, curriculum, and school environment domains. The results also revealed that there were statistically significant differences in the challenges and obstacles faced by the teachers in terms of the experience variable. The study, thus, recommends adopting a more effective strategy to improve the school environment and having a suitable psychological context for female English teachers in order to enhance the quality of the students' learning outcomes.
\end{abstract}

Keywords: Teaching English, Female English teachers, Challenges, Academic experience, Jordan

\section{Introduction}

Nowadays, teachers face many challenges, such as the spread of behavioural and academic problems that threaten the educational system in most of the schools. These problems have a direct influence on the teaching and learning process. These include forgetting school equipment, frequent absenteeism, poor concentration, hyperactivity, inappropriate talk in the classroom, disobedience, aggressiveness, and refusal to complete tasks and schoolwork (Al-Amarat, 2017).

English language teaching is a difficult mission in countries that regard English as a foreign language such as Jordan where the teaching of English has grown quickly in recent years (Alkhawaldeh, 2010). This rapid increase combined with the great diversity of English language learners represent a challenge to English language teachers in this country and in other countries that have a similar situation. As a result, there is a need to improve educational policies, curricula, materials, and management, as well as teacher training (Khong \& Saito, 2013). In particular, teachers struggle with their beliefs and training, the reality of the classroom, and the requirements of parents and students and hence, all these factors need to improve quickly (Paran, 2012).

Because of the above changes, teachers' knowledge and skills have to increase; English language teachers today need to be critical thinkers in order to face these challenges and select suitable classroom approaches. In addition, they need to immerse themselves in the literature of different fields such as psychology, sociology, and instructional science (Karatas \& Karaman, 2013). The knowledge and skills they will learn from exploring these disciplines may help them improve their approach and teaching methods which, in turn, may improve the teaching-learning experience.

One main element in preparing English language teachers is the competency and knowledge to make them effective teachers. Within the framework of professional development, various types of knowledge have been 
studied, with a focus on content knowledge, pedagogical content knowledge, and curriculum knowledge (Alkhawaldeh, 2010). This framework helps teachers recognise the importance of thinking about their current knowledge and reflect on their experience, which helps them decide how they can develop their capacity to plan their future teaching methods by using the above types of knowledge. This may demonstrate that having one type of knowledge is insufficient on its own to make an individual a good teacher as other types of knowledge are essential to improve their professional development as teachers.

In addition, classroom management is considered the most important element in the teaching process and a basic requirement, but is also considered one of the main problems facing teachers because it consumes so much time and effort, and is a critical factor in the teacher's success or failure (Al-Amarat, 2017; Burden, 2020). This is because effective teaching and learning cannot occur in a poorly managed classroom. Specifically, if students are disrespectful and disorderly with no clear procedures and rules to guide their behaviour, chaos becomes the norm, making both teachers and students suffer.

English language teaching has always been a subject of concern for education policymakers around the world because teaching English as a foreign language (EFL) is not easy and requires a good and effective teacher (Brwon, 2009; Çelik, Arikan, \& Caner, 2013). For this reason, teachers need to be knowledgeable in various teaching methods and skills to be able to teach English language effectively. Moreover, teaching EFL in the Middle East and Jordan in particular has been the subject of researchers such as Karatas and Karaman (2013) and Alkhawaldeh (2010), particularly the challenges and obstacles that teachers face.

In general, teachers and some principals believe that the teaching environment must be orderly and quiet, thinking that a quiet classroom means effective teaching. Although sharing ideas and information via various communicative activities taking place at the same time may lead to noisy classrooms, it would be a mistake to conclude that in such classrooms students are not learning (Al-Amarat, 2017). The data to support this argument was provided by Al-Amarat (2017) based on a sample of 196 teachers from a public school in Tafila province.

In this context, this study reviews the obstacles facing female teachers in secondary schools in the Al-Qaser directorate in Al-Karak city in Jordan. It also tries to suggest some solutions to solve such obstacles in order to provide better services to female school students in Jordan. Consequently, the educational leaders and decision makers in the Jordanian Ministry of Education can suggest some tips to minimise the side effects of these obstacles in order to enhance both teachers' and students' learning and teaching experiences. This study focuses on the challenges encountered by female teachers in Al-Karak, since such a community has not been given due attention. In addition, based on the researchers' experience as teachers in this province in Jordan, these challenges are increasing with no solution in sight due to the lack of research in this domain. Thus, this study aims to bridge this gap. This study is important as it explores an under-investigated community in Jordan and attempts to provide solutions to the challenges they encounter, and thus, improve the learning environment and the well-being of the female teachers involved.

\section{Literature Review}

\section{Key Points}

Three main factors need to be considered at this point. The first is the obstacles or barriers that prevent the action or progress of a process; an obstacle can be material or nonmaterial, but always stands in the way of progress (Dhillon \& Wanjiru, 2013). In this study, it is the number of obstacles faced by female English language teachers at Al-Qaser Directorate of Education. For example, female teachers do not have enough training pertaining to modern teaching methods, e.g. using technology inside the classroom. The second point is female teachers of the English language to students in the Ministry of Education, Jordan. ${ }^{1}$ This category of teachers was selected because they are amongst the most who encounter challenges in Al-Karak. This is because the majority of schools in that governorate are public ones; these schools face considerable difficulties in hiring

${ }^{1}$ It is worth pointing out that male English teachers may have the same difficulties/obstacles. However, due to time limitations and the conservative nature of Al-Karak city, it was difficult for the first author/researcher to collect data from male teachers. Thus, it is recommended to conduct another study investigating challenges faced by male teachers. 
specialized female English teachers because most of these teachers prefer to work in the capital of Jordan, Amman. The final factor to consider is the secondary school context, which consists of two levels, from 11th to 12 th grades.

\section{Conceptual Framework}

The level of education of a country determines its place among other countries in the world. In particular, countries with high achievement levels in education and research lead the world, because a good education level in any country will affect living standards and convert the population of a country into useful human capital; as such, it is an agent of positive change (Saeed et al., 2013).

English is now the lingua franca of the world and is the most prevalent global language, embraced by almost all nationalities. No longer limited to its native nations, such as the UK and USA, the number of people who use English as a means of communication greatly exceeds the number of its native speakers (Ahmad, 2003). Military, political, and cultural factors have all played a significant role in the deployment of English around the world, and the technological revolution and new e-learning systems have also contributed to English becoming the most important means of communication at present. As access to technology increases worldwide, there is an increased need to learn English. Roughly, 55\% of all written content on the internet is in English. It is the language of science and technology, and the first official language of the United Nations. Hence, English is the most popular language even within regions where native languages are considered necessary (Alzayyat, 2014).

\section{Teaching English in Jordan}

In Jordan, English was the only foreign language to be taught before and after the independence of 1946. After independence, English was taught in all Jordanian schools from the early age of eleven, for just one hour once per week. After the 1990s, English began to be taught alongside Arabic in all Jordanian schools from the age of six. This has given the English language a unique position in Jordan (Awajan, 2010). Today, English remains one of the most important foreign languages that a student learns during the last three grades of high school education. The number of hours per week allotted to English varies from one discipline to another: one hour in sciences, and two hours in humanities. However, in the 1990s the number of hours allotted to English changed, for example seven hours in sciences and nine in humanities. This means English is being used extensively in all Jordanian schools compared to previous years (Alzyat, 2014).

English is taught in Jordanian schools as a foreign language, due to its importance as the language of communication in all fields in the world (Awajan, 2010). English teaching in Jordan is a necessity for academic, work, and personal purposes. First, it forms the basis of the scientific knowledge that will be used in academic areas such as business, health, computing, and arts. Second, the labour market requires job seekers to have a good command of English to facilitate communication with clients and businesses. Being fluent in English helps the job seeker to find a better job; and, therefore, English is needed to meet and communicate with people, to travel, and to use the internet and social media (Alkhawaldeh, 2010).

In 1962, there were fewer than 22 teachers of English in secondary schools, but the number increased dramatically from 1962-2013, and now there are thousands teaching in Jordanian secondary schools. This has also increased the number of people learning English, because most jobs in Jordan require it from their employees or candidates (Alzyat, 2014). English now even competes with Arabic, and in many sectors English is the first language used, for instance, in the tourism sector, the Ministry of Foreign Affairs, higher scientific study, businesses, and airports. This has given English a unique position in Jordan, and also increased its spread across the country (Awajan, 2010).

As far as English language teaching objectives in secondary schools are concerned, the Jordanian Ministry of Education (MOE) works on planning, upgrading, implementing, and evaluating all educational components for students, teachers, and staff, including curricula, educational materials, facilities, and other related issues. Concerning the objectives of teaching English language culture as set by the Jordanian Ministry of Education, there are multiple goals and outcomes that lay behind teaching English to Jordanian pupils ${ }^{2}$. The Ministry indicates that "the EFL curriculum should help the students to internalize Islamic and Arabic culture, which

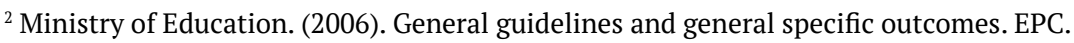


should be used to understand, appreciate, and interact with people of different identities" (English Language Curriculum, MOE, 2006, p.9).

The $\mathrm{MOE}^{3}$ has laid down a list of guidelines that stress the integral role of foreign language education in developing Jordanian students' language skills (listening, speaking, reading, and writing). The guidelines assert the following: an emphasis of knowledge economy competencies, integration of information and communication technologies, a new role for students by giving students opportunities to define their own ways of reaching outcomes, a new role for teachers to help students learn and communicate effectively by giving greater consideration to individual learning needs, and a variety of instructional strategies to ensure that all students achieve learning goals.

Moreover, the $\mathrm{MOE}^{4}$ set a group of goals that must be achieved at each grade in the English language curriculum. Notably, the goals relating to the secondary curriculum aim to prepare students in a number of ways. First, they focus on communicating ideas, information, and feelings effectively for a variety of purposes in written, spoken, and visual forms to interact and cooperate with others to achieve goals. Second, they would like students to be able to think critically, and to make a value judgment on texts in light of Islamic and Arab culture and values. Third, they would like the students to acquire a positive attitude towards English and realise its importance as a means of promoting mutual understanding among peoples and countries. Finally, students need to be able to apply the skills and strategies that are necessary for the positive utilisation of electronic technology in lifelong learning contexts and in real-life situations to gather and produce new ideas.

\section{English Language Teachers}

Education is a process of behavioural change and development that occurs continuously throughout every stage of life. Teachers are active in every stage of that process. The formation of desirable behaviour in students is closely linked to the motivation levels of the teacher, as well as the teacher's attitude and behaviour. Low motivation levels in the teacher, who is in a critical position in the education and schooling process, has a negative impact on the achievement of high standards in education (Kocabas, 2009).

English language teachers have great responsibility, should make extra effort, and be more motivated than other teachers in order to improve foreign language achievement. Therefore, preparing future foreign language teachers for their careers is a complex process that requires reflection, opportunities to apply theory to real-life situations, and a network for the exchange of ideas and support (Gardner, 2001). English language teachers use a range of course books and materials, plus a variety of audio-visual aids. A strong emphasis is placed on dialogue and role-playing, but more formal exercises, language games, and literature are also used. There are many typical tasks that may be carried out by teachers, including: classroom management; planning, preparing, and delivering lessons to a range of classes and age groups; preparing and setting tests, examination papers, and exercises; marking and providing appropriate feedback on oral and written work; devising, writing, and producing new materials, including audio-visual resources; organising and being involved in social and cultural activities such as sports competitions, school parties, dinners, and excursions; attending and contributing to training sessions; participating in marketing events for the language school; preparing information for inspections and other quality assurance exercises; freelance teaching on a one-to-one basis; and basic administration, such as keeping student registers and attendance records (Burden, 2020; Teevno, 2011).

Additionally, teachers must have a good command of English and a relevant qualification, and also show evidence of the following characteristics: a friendly and confident manner; good planning and organisation skills; the ability to work under pressure; flexibility and an adaptable teaching style; creative skills and ideas for planning practical and interesting lessons; excellent spoken and written communication skills; effective listening skills; and sensitivity, tolerance, and patience (Khong \& Saito, 2013).

Teachers can face difficulties when adapting to emerging issues in the changing ELT (English Language Teaching) praxis. For instance, in past years, shifts in focus have included changes in teaching the four language skills, with an interest in discoursal functions, the role of technology in instructional processes, and

\footnotetext{
3 Ibid

${ }^{4}$ Ibid
} 
more emphasis on the role played by learners; in this regard, teachers are also "battling with the conflict between their beliefs, their training, the realities of the classroom, the demands of parents and learners, [and] the requirement to demonstrate immediate attainment" (Paran, 2012, p.457).

Due to these and other changes, expectations of teachers' knowledge and skills have increased. Today's language teacher is expected to think critically, reflect on changes in the world, and implement appropriate teaching methods in the classroom. To develop knowledge that will support effective teaching, language teachers need to immerse themselves in the literature of various fields such as psychology, sociology, and instructional science (Canagarajah, 2012).

With the growing movement toward cooperative learning, more teachers are using activities in which students take an active role. Sharing ideas and information with various activities occurring at the same time can make for noisy classrooms, but, as noted above, it would be a mistake to conclude that students are not learning (Hamasha, 2000).

\section{Obstacles Facing English Language Teachers}

English language teachers face various academic, administrative, and professional challenges. This section explains these obstacles in general.

\section{Obstacles as a Result of Professional Development}

The success of any educational system depends on good and well-resourced teachers. Although teachers cannot easily be replaced with any kind of instructional materials, teaching is a profession that needs frequent updating. In this vein, female teachers should be alert to new changes around the world. Likewise, they need to remain continuously abreast of the latest theories, research, and other additions to the pool of knowledge. It has been observed that female teachers who are not competently sound and up to date are unable to handle the diverse changes and variations in their society, country, and humanity at large. On the contrary, female teachers who obtain the latest knowledge and develop their skills can effectively manage the process of teaching and learning, and indeed they teach and learn better (Filter \& Horner, 2009).

Effective female teachers also need to be successful learners. Nevertheless, the professional development of female teachers has not been given appropriate attention in Pakistan. As a result, they may be less able to solve students' academic and societal issues. Additionally, it is possible that students graduating from (government) schools have weaker communication skills and find it hard to deal with the problems of life (Elyas \& Al Grigri, 2014).

\section{Obstacles as a Result of Physical and Learning Resources}

The lack of teaching and learning aids in schools creates difficulties in the teaching process, especially for females. Some schools for girls do not even have basic materials such as blackboards, attendance registers, offices, libraries, laboratories, and up-to-date books. The majority of girls' schools also have a lack of classrooms or proper playgrounds for the physical development of both students and teachers (Dhillon \& Wanjiru, 2013). This has created serious problems for female teachers, as they cannot provide the students with wider opportunities for learning and development. Even though teachers are expected to cover the entire curriculum, under the given conditions they fail to create meaningful a learning environment in schools (Hussain, 2001).

\section{Obstacles as a Result of Community Involvement}

Teachers are not given due respect in their society, and thus the teaching profession is constantly losing qualified people in favour of other professions. Only those of low calibre and ability join the teaching profession. Schools are communities in miniature, and teachers are important change agents, mentors, and academic leaders in society. Teachers regularly face negative remarks from parents, as any the poor performance of students is linked to the performance of the teachers (Deaeghere, Williams, \& Kyeyune, 2009), without the realisation that the performance of students is also associated with the school administration and parents. It is therefore an injustice only to hold teachers responsible for the bad results of students on examinations. There is a lack of awareness by parents and the community that they are equal stakeholders in the development of the students (Cho \& Reich, 2008). 


\section{Obstacles as a Result of Overloaded Classes}

There are no measures of work in some schools, either due to the ignorance of the administration or lapses by female teachers in setting a procedure for school work. In many schools, mostly in far-flung areas, there is a shortage of female teaching staff, and this situation overburdens other teachers in the schools (Borich \& Tombari, 2004) and creates more pressure on teachers, which can have negative impacts on their health. In this context, teachers try to cover the syllabus at the cost of the quality of the teaching and learning. Teachers cannot pay individual attention to many students, even though this is a great psychological and social need for this (Dhillon \& Wanjiru, 2013).

\section{Obstacles as a Result of Supervision}

The process of supervision is filled with bureaucratic underpinnings. In essence, the purpose of supervision is to develop and improve the performance of teachers and students. Conversely, the process of supervision is characterised by the notion of inspection, during which time supervisors can create an environment of fear (Khong \& Eisuke, 2014). The supervisors behave like kings and treat the teachers like slaves and inferiors. This trend has created mistrust and affected the spirit of cooperation among teachers, and between teachers and the administration. Instead of providing constructive feedback, the supervisors give orders to the teachers, and hence no improvement takes place (Cho \& Reich, 2008).

\section{Obstacles as a Result of Coordination and Cooperation}

The system of education must have a mechanism of coordination. This problem has taken root due to weak communication between policymakers, staff, parents, and the community. The poor coordination in the system has promoted misunderstandings between these stakeholder groups (Hararsh \& Kawaldh, 2009). Teachers remain on the receiving end in all areas, such as in the making of the curriculum or any other education policy; that is, teachers participate only in the implementation not in the development. This leads to the creation of a culture of blame. There is even a lack of coordination between teachers and principals (Khong \& Saito, 2013).

\section{Obstacles as a Result of the Prevailing Curriculum}

Curriculum development is a centralised activity, and schools are supposed to implement the set curriculum without manipulation. In this regard, the teachers' role is that of implementer. They cannot contribute to the curriculum development process or its evaluation, and they are not provided with refresher courses to stay in line with updated syllabi (Cho \& Reich, 2008). These factors have left teachers ignorant of many aspects of the curriculum, and this ultimately affects not only their own performance but also the process of teaching and learning in schools. In many cases, teachers are unaware of the aims or goals of the curriculum for certain levels and this creates gaps in the understanding of the curriculum and its effective implementation. However, in developed countries, teachers are invited to participate in the process of curriculum design and development, and indeed their input is considered vital for the improvement of the education system (Deaeghere, Williams, \& Kyeyune, 2009).

\section{Obstacles as a Result of Textbooks}

Textbooks are a very important aspect of the teaching and learning process, and their development is a highly specialised area of curriculum development. However, school teachers face a problem of instruction due to the non-availability of quality textbooks. Due to the culture of multilingualism and medium of instructions in schools, there is an environment of uncertainty, difficulty, and fatigue, and a lack of understanding by both female teachers and students. Moreover, there is a lack of training of female teachers on how to implement, or explain concepts from, different textbooks (Dhillon \& Wanjiru, 2013).

\section{Previous studies}

Several researchers (e.g. Alkahtani, 2017; Alzyaa, 2014; Seals et al., 2017; Sentance \& Csizmadia, 2017; Tambwe, 2019 inter alia) have investigated the challenges that school teachers encounter. For example, Alkahtani (2017) noted that the greatest challenges were the lack of training and the work equipment. Alzyaat (2014) studied the problems of teaching the English language and culture in Jordanian public schools. The sample of this study consisted of a) 400 students: 231 females and 169 males, and b) 50 English language teachers: 37 females and 13 males. Two questionnaires were designed to collect data from the teachers and students, respectively, and a quantitative method was used to analyse the data obtained. The findings showed that the problems of 
teaching the culture associated with the English language already existed among students, teachers, and the English language curriculum, which constituted a gap in teaching and learning English.

Elyas and Al Grigri (2014) aimed at identifying the obstacles to teaching English in public schools in Saudi Arabia from the viewpoint of teachers and supervisors. A mixed-method approach was adopted using two instruments for data collection: a closed-ended questionnaire and an open-ended interview, eliciting quantitative and qualitative data. A total of 50 questionnaires were distributed to teachers and supervisors of the English language, and followed up with open-ended interviews with six English language teachers and supervisors. The findings revealed that there was: a scarcity of development programmes and in-service training, weak in-service training programmes, low student motivation, an overuse of traditional teaching methods, infrequent use of teaching aids and modern technology, and a lack of school supplies and language laboratories.

A study by Akasha (2013) aimed to cover the challenges facing Arabic-speaking ESL students and teachers in middle school classrooms. Two Arabic-speaking ESL students and eight teachers in public middle schools in Washington State participated in this exploratory study. The sample consisted of 100 students and 100 teachers. Data sources included teacher and student interviews, classroom observations, and a parent survey. The study concluded that several important challenges for teachers and students exist, including a lack of time, language support, and cultural knowledge.

As far as teaching experience is concerned, Kini and Podolsky (2016) reviewed 30 students concerning how teaching experience increases over time. The researchers concluded that teaching experience is positively associated with students' attendance and achievement. Similarly, Al-Amarat (2017) conducted a study aimed at investigating the classroom problems facing teachers in public schools in Tafila province and the proposed solutions. The sample consisted of 196 teachers and the results indicated that there were many behavioural and academic problems facing these teachers. The study also found statistically significant differences between gender, level of school, and teaching experience in the behavioural problems for males in the basic school and those with less than five years' work experience.

Izadpanah (2011) investigated teachers' opinions and beliefs on the place of target cultural information in English language teaching, as well as related practices and applications in EFL classrooms in the higher education context. The study showed that the teachers mostly defined culture in the sociological sense, such as values and beliefs. Their definitions in the framework of ELT slightly shifted towards more visible culture, such as food and clothing. The study also revealed teachers' positive attitudes towards incorporating cultural information in their instruction.

Awajan (2010) investigated the motivational level of English language teachers in Jordan and identified teachers' motivational factors. To achieve the aim of the study, the researcher used semi-structured interviews and an English language questionnaire. A sample of 100 secondary school teachers from Amman's Second Educational Directorate were randomly selected to respond to the questionnaire. The study showed that they were motivated because they liked their jobs, teaching would help them in their future, teaching gave them security for their families, and it is prestigious to be an English language teacher.

A study by Filter and Horner (2009) investigated the relationship between problem behaviours and academic variables in classrooms. Functional behavioural assessments were conducted with two elementary school fourth graders. Two behavioural support interventions were developed for each participant. One was designed using a competing pathways model that combined behavioural and academic support, and linked the intervention components to the functional assessment results. The second was drawn from the literature. The results indicated that function-based academic interventions resulted in significantly fewer problem behaviours than were observed during non-function-based interventions. The results lend support to the idea that interventions for problem behaviours in the classroom context will be more successful if based on functional behavioural assessments.

Hararsh and Kawaldh (2009) aimed to identify patterns of control implemented by classroom teachers to maintain discipline in the classroom in the Al-Mafraq District of Education. The study sample consisted of 210 teachers who were given a questionnaire covering 35 data items. The results indicated that the patterns of 
classroom interaction were as follows: proactive type style, insulting, and authoritarian. Furthermore, CluniesRoss, Little, and Kienhuis (2008) investigated the relationship between primary school teachers' self-reported and actual use of classroom management strategies. The sample consisted of 97 teachers from primary schools in Melbourne, and again data were collected by questionnaire. The findings indicated that teacher self-reports accurately reflected actual practice in that relatively minor forms of student misbehaviours were a common concern for teachers. Teachers spent a considerable amount of time on behavioural management issues. In addition, the findings revealed that the use of predominantly reactive management strategies had a significant relationship with elevated teacher stress and decreased student on-task behaviour.

Hamasha (2000) aimed to identify the administrative problems that faced newly appointed teachers in the first three grades of schools in Irbid and to define these problems in terms of sex and qualifications. The study revealed a significant relationship $(\alpha=0.05)$ in the degree to which administrative problems exist for newly appointed teachers of grades 1-3 due to gender, but there was no significance $(\alpha=0.05)$ in the degree to which administrative problems existed for these teachers due to their qualifications.

Based on the previous literature, it can be concluded that a few studies have examined the problems that face female English language teachers. This study investigates the academic challenges and obstacles faced by English female teachers in secondary schools in the Jordanian setting of Al-Qaser directorate; although it examines the obstacles they face, these are not linked to their gender per se. In addition, the Jordanian educational process faces many obstacles related to the nature of the education process, and therefore hard work is needed to bridge the gap between the current educational reality and the desired situation. The significance of this study stems from; firstly, its focus on the types of academic obstacles facing an underinvestigated teacher community in Al-Karak province in Jordan, namely female English language teachers. Secondly, its aim to motivate these teachers to face their obstacles and find a solution for them. Finally, this study aims to encourage decision makers to take steps that help these teachers solve such problems. In particular, the study seeks to answer the following questions:

1. What level of obstacles is faced by female English teachers in secondary schools at Al-Qaser Directorate of Education from their own perspective?

2. Are there any statistically significant differences $(\alpha \leqslant 0.05)$ in the obstacles faced by female English teachers in secondary schools at Al-Qaser Directorate of Education due to the teachers' experience, age, or qualifications?

\section{Methodology}

\section{Population and Sample}

The population of the study consisted of all female teachers in secondary schools in the Educational Directorate of Al-Qasar, totalling 250 female teachers, and the study sample was comprised of 150 female teachers who were randomly selected. Table 1 shows the sample distribution.

Table 1

Sample Distribution

\begin{tabular}{llcc}
\hline & \multicolumn{1}{c}{ Variables } & Frequency & Percentage (\%) \\
\hline \multirow{3}{*}{ Qualification } & Diploma & 20 & 13.33 \\
& Bachelor's Degree & 100 & 66.67 \\
& Postgraduate & 30 & 20 \\
\hline \multirow{3}{*}{ Experience } & Less than 5 years & 40 & 26.67 \\
& From 5-10 years & 80 & 53.33 \\
\hline \multirow{3}{*}{ Age } & From 20-25 years & 30 & 20 \\
& From 26-34 & 15 & 10 \\
& More than 35 & 90 & 60 \\
\hline
\end{tabular}




\section{Instruments}

A questionnaire was designed consisting of 20 items and three dimensions (see Appendix I), and each question used a five-point Likert scale. To check its validity, the questionnaire was given to a number of experts and professors at Mutah University, and to supervisors and teachers to ascertain the appropriate wording for the questionnaire items. In addition, the validity check led to added items and domains, thus the final instrument contained 29 items and covered five dimensions (school environment, students, community and parents, teachers' skills, and the curriculum). For reliability, Cronbach's alpha was used to measure the stability of the questionnaire and the value obtained was 85.14, which is considered suitable for the study. The participants voluntarily participated in the study and their identities were anonymised.

\section{Procedure}

Several steps were taken to conduct this study. First, the necessary permissions were obtained to conduct the study. Second, the study population was identified as female English language teachers in the Al-Qaser Directorate of Education. Third, the questionnaire was prepared and its validity and reliability were extracted. Fourth, the questionnaire was personally distributed to the study sample; 150 questionnaires were returned, which is valid for statistical analysis. Fifth, the data were collected and analysed using the Statistical Package for Social Sciences System (SPSS, ver.20). Finally, the results of the study were extracted and discussed, and a set of recommendations were proposed.

\section{Analysis}

To analyse the data, means, standard deviation, and a two-way ANOVA were used.

\section{Results and Discussion}

\section{Results Related to the First Question}

What level of obstacles is faced by female English teachers in secondary schools at Al-Qaser Directorate of Education from their own perspective?

The findings and statistical analysis for this part are illustrated in Table 2.

Table 2

Means and Standard Deviation of the First Question

\begin{tabular}{clcccc}
\hline No & & Dimensions & Means & Std. Deviation & N \\
\hline 1 & School Environment & 3.58 & 1.16 & 150 \\
2 & Students & 3.83 & 1.26 & 150 \\
3 & Community and Parents & 3.80 & 1.25 & 150 \\
4 & Teachers' Skills & 3.59 & 1.19 & 150 \\
5 & Curriculum & 3.65 & 1.24 & 150 \\
\hline Total & & $\mathbf{3 . 6 9 6 3}$ & $\mathbf{1 . 2 2 6 6}$ & $\mathbf{1 5 0}$ \\
\hline
\end{tabular}

Table 2 shows that the mean average for the answers to the first question $(m=3.69)$ was high and the standard deviation (SD) was 1.22. As shown in Table 1, the student dimension came first $(\mathrm{m}=3.83)$, followed by the community and parents dimension $(\mathrm{m}=3.80)$, the curriculum dimension $(\mathrm{m}=3.65)$, the teachers' skills dimension $(m=3.59)$, and finally the school environment dimension $(m=3.58)$. At the dimension level, the results were as follows: 
First Dimension: School Environment

Table 3

Means and SD of the First Dimension

\begin{tabular}{clccc}
\hline No & \multicolumn{1}{c}{ Items } & Means & SD & N \\
\hline 1 & School buildings and environments are not suitable & 3.66 & 1.21 & 150 \\
2 & Emotional and psychological support from the school principal is not enough & 3.50 & 1.11 & 150 \\
& & 3.50 & 1.18 & 150 \\
3 & Classes are crowded & 3.72 & 1.23 & 150 \\
4 & School facilities are suitable & 3.59 & 1.19 & 150 \\
5 & The classroom is always clean & 3.65 & 1.24 & 150 \\
6 & English language teachers' opinions / suggestions are taken seriously & 3.46 & 1.16 & 150 \\
7 & Safety at school is taken into consideration & 3.58 & $\mathbf{1 . 1 6}$ & $\mathbf{1 5 0}$ \\
\hline Total & &
\end{tabular}

As shown in Table 3, item 1 'school facilities are suitable' had the highest mean score $(\mathrm{m}=3.72)$, while that of 'safety at school is taken into consideration' had the lowest mean score $(\mathrm{m}=3.46)$; this means that female teachers faced many challenges in the school environment, for example the lack of safety. Moreover, the insufficient emotional and psychological support from the school principal was also a major stumbling block facing English female teachers. These results reveal that real obstacles were faced by the female English teachers in secondary schools related to the school environment. This may be attributed to the fact that the Directorate is not concerned with the quality of buildings and number of classes, or the lack of appropriate student seating or modern teaching tools. This result is in line with Hussain (2001) who noted that the school environment created many challenges for female teachers since they cannot provide the students with enough good opportunities for learning and development in a meaningful and suitable learning environment.

\section{Second Dimension: Students}

\section{Table 4}

Means and SD of the Second Dimension

\begin{tabular}{|c|c|c|c|c|}
\hline No & Items & Means & SD & $\mathbf{N}$ \\
\hline 1 & Students understanding what is taught & 3.64 & 1.16 & 150 \\
\hline 2 & Neatness/cleanliness of the students & 3.83 & 1.25 & 150 \\
\hline 3 & Students' level in English classes & 3.91 & 1.25 & 150 \\
\hline 4 & Most learners commonly use mother tongue in school & 3.89 & 1.19 & 150 \\
\hline 5 & $\begin{array}{l}\text { Pupils have difficulties with English sounds that are not found in their mother } \\
\text { tongue }\end{array}$ & 3.90 & 1.24 & 150 \\
\hline Total & & 3.83 & 1.26 & 150 \\
\hline
\end{tabular}

As shown in Table 4, the item 'students' level in English classes' had the highest mean score $(m=3.91)$, while the item 'students understanding what is taught' had the lowest $(m=3.64)$. This result may mean that the female teachers faced many challenges in dealing with students, including the fact that most learners used their mother tongue in school and students had difficulties with English sounds not found in their mother tongue. This result reveals that there were real obstacles facing these female English teachers related to their students, who did not care about their English language class and used Arabic as their mother tongue, which made English learning difficult. Additionally, some students could not understand what was being taught and they did not ask for help with the lesson because they did not know the importance of the English language in daily life. This issue can be resolved through making their class environment more engaging and helping them realise the impotence of English Language in their classes and their daily life (Hazaymeh \& Altakhaineh, 2019; Zibin \& Altakhaineh, 2019). 


\section{Third Dimension: Community and Parents}

\section{Table 5}

Means and SD of the Third Dimension

\begin{tabular}{clccc}
\hline No & Items & Means & SD & N \\
\hline 1 & Parents showing positive attitudes towards English language teachers & 3.59 & 1.15 & 150 \\
2 & Parents are unaware of the importance of English language & 4.35 & 1.16 & 150 \\
3 & Parents cooperate with English language teachers & 3.61 & 1.17 & 150 \\
4 & English language teachers are respected by the community & 3.66 & 1.26 & 150 \\
\hline Total & & $\mathbf{3 . 8 0}$ & $\mathbf{1 . 2 5}$ & $\mathbf{1 5 0}$ \\
\hline
\end{tabular}

As shown in Table 5, the item 'parents are unaware of the importance of English language' scored the highest $(\mathrm{m}=4.35)$, while the item 'parents show positive attitudes towards English language teachers' scored the lowest $(m=3.59)$. This result means that students' parents did not care about their children's English language learning. Therefore, these female English teachers faced serious obstacles related to the community and parents, as the parents did not know the importance of English language, and did not cooperate with the teachers or respect them. This result concur with the findings of Cho and Reich (2008) who noted that there is a lack of awareness by parents and the community that they are partially responsible for their children's behaviour and academic achievements. In a similar vein, the poor coordination between parents and teachers causes delaying in the development of the students (Hararsh \& Kawaldh, 2009).

\section{Fourth Dimension: Teachers Skills}

\section{Table 6}

Means and SD of the Fourth Dimension

\begin{tabular}{|c|c|c|c|c|}
\hline No & Items & Means & SD & $\mathbf{N}$ \\
\hline 1 & Teachers are well prepared to teach English at all levels in high school & 3.56 & 1.15 & 150 \\
\hline 2 & There are no conferences related to English language teaching and learning & 3.50 & 1.16 & 150 \\
\hline 3 & Teacher needs to enhance workshops on using specific aids for teaching English language & 3.68 & 1.15 & 150 \\
\hline 4 & Teachers need many training programmes & 3.55 & 1.17 & 150 \\
\hline 5 & English language teachers have a desire to teach & 3.56 & 1.14 & 150 \\
\hline 6 & $\begin{array}{l}\text { English language teachers have good knowledge and experience with a variety of teaching } \\
\text { methods }\end{array}$ & 3.55 & 1.16 & 150 \\
\hline 7 & English language teachers collaborate with each other & 3.71 & 1.14 & 150 \\
\hline 8 & EFL teachers have team spirit & 3.70 & 1.15 & 150 \\
\hline 9 & $\begin{array}{l}\text { English language teachers have knowledge of the language's systems (phonetics, morphology, } \\
\text { phonology, and syntax) }\end{array}$ & 3.57 & 1.16 & 150 \\
\hline 10 & English language teachers are aware of English language methods & 3.56 & 1.14 & 150 \\
\hline Total & & 3.59 & 1.19 & 150 \\
\hline
\end{tabular}

As shown in Table 6, the item 'English language teachers collaborate with each other' scored the highest $(\mathrm{m}=3.71)$, while the item 'there are no conferences related to English language teaching and learning' scored the lowest $(\mathrm{m}=3.50)$. This result means that the female English language teachers tried to work well, but were faced with many challenges, such as a lack of professional development opportunities related to English language teaching. This result reveals that the female English teachers faced obstacles related to their teaching skills, which may be attributed to the absence of any courses or training workshops for teachers of English. Moreover, when an English teacher is committed to a specific book, she does not gain new experience, and so the teacher faces academic challenges teaching students. These results are in line with Alkahtani (2017) who suggested that the greatest challenges teacher regularly encounter were a lack of training and work equipment. 


\section{Fifth Dimension: Curriculum}

\section{Table 7}

Means and SD of the Fifth Dimension

\begin{tabular}{clccc}
\hline No & \multicolumn{1}{c}{ Items } & Means & SD & N \\
\hline 1 & $\begin{array}{l}\text { Pressure from curriculum demands inhibits creative and innovative language } \\
\text { teaching }\end{array}$ & 3.63 & 1.13 & 150 \\
2 & Simultaneously teaching English and Arabic has no effect on acquiring English & 3.65 & 1.13 & 150 \\
3 & Local English varieties are more common as opposed to Standard English & 3.66 & 1.15 & 150 \\
\hline Total & & 3.65 & $\mathbf{1 . 2 4}$ & $\mathbf{1 5 0}$ \\
\hline
\end{tabular}

Table 7 shows that the mean average for the answers regarding the curriculum was $(m=3.65)$, or high, and the SD was 1.24. Table 7 also shows that the item on local English varieties being more common as opposed to Standard English had the highest score $(m=3.66)$, while the item on pressure from curriculum demands inhibiting creative and innovative language teaching had the lowest $(m=3.63)$. This result means that the curriculum created some challenges for the female English language teachers and reveals that real obstacles were faced by them related to the curriculum. This may be due to the fact that the English language curriculum does not achieve the desired educational goals and that the English language curriculum development was not commensurate with the requirements of the times.

\section{Results Related to the Second Question}

Are there any statistically significant differences $(\alpha \leqslant 0.05)$ in the obstacles faced by female English teachers in secondary schools in the Al-Qaser Directorate of Education due to teachers' experience, age, or qualifications?

This question is divided into three parts. Firstly, we investigated whether there were any statistically significant differences $(\alpha \leqslant 0.05)$ in the obstacles faced due to teachers' experience levels. To answer this question, a oneway ANOVA test was used, as shown in Table 8.

Table 8

One-Way ANOVA Test of the Experience Variable

\begin{tabular}{lcccc}
\hline \multicolumn{1}{c}{ Variables } & Means & SD & F & Sig \\
\hline Less than 5 & 3.67 & 1.16 & 8.845 & 0.000 \\
5 to 10 & 3.69 & 1.18 & & \\
11 and more & 3.71 & 1.15 & & \\
\hline
\end{tabular}

Table 8 shows that the (f) value was (8.845) and sig (0.000), which means that there were statistically significant differences in the academic challenges and obstacles faced by these female English teachers due to teachers' experience level. The more experienced the teachers are, the more they are able to meet challenges and resolve problems related to students' achievements (Kini \& Podolsky, 2016). In fact, Kini and Podolsky (2016) concluded that teachers continue to improve in their effectiveness as they gain more experience in their teaching profession.

Second, we examined whether there were any statistically significant differences $(\alpha \leqslant 0.05)$ in the obstacles faced due to the teachers' age. To answer this question, a one-way ANOVA test was used, as shown in Table 9.

Table 9

One-Way ANOVA Test of the Age Variable

\begin{tabular}{lcccc}
\hline \multicolumn{1}{c}{ Variables } & Means & SD & F & Sig \\
\hline Less than 5 & 3.67 & 1.16 & 8.845 & 0.000 \\
26-34 years & 3.83 & 1.12 & & \\
35 and more & 3.81 & 1.17 & & \\
\hline
\end{tabular}

Table 9 shows that the (f) value was 0.355 and sig 0.785 , which means there were no statistically significant differences in the academic challenges and obstacles faced by these female English teachers due to their age. 
Third, we investigated whether there were any statistically significant differences $(\alpha \leqslant 0.05)$ in the obstacles faced due to the teacher's qualifications. To answer this question, a one-way ANOVA test was used, as shown in Table 10.

Table 10

One-Way ANOVA Test of the Qualifications Variable

\begin{tabular}{lcccc}
\hline \multicolumn{1}{c}{ Variables } & Means & SD & F & Sig \\
\hline Diploma & 3.44 & 1.26 & 2.254 & 0.106 \\
Bachelor & 3.91 & 1.15 & & \\
Postgraduate & 3.73 & 1.18 & & \\
\hline
\end{tabular}

Table 10 shows that the (f) value was (2.254) and $p$-value (0.106), which means there were no statistically significant differences in the academic challenges and obstacles faced by the female English teachers due to the teachers' highest education degree. This agrees with Hamasha (2000) who found that there was no significance $(\alpha=0.05)$ in the degree to which administrative problems exist for these teachers due to their qualifications.

It is clear that real obstacles were faced by these female English teachers, including school environment, students, community and parents, teachers' skills, and the curriculum. The findings are consistent with those of several other studies. In terms of scarcity and weakness of development and in-service training programmes, the current study agrees with Hamasha (2000) and Clunies-Ross, Little, and Kienhuis (2008). This result may be due to the level of organisation and management applied by the Al-Qaser Directorate not being sufficiently efficient, as there are many obstacles in the school environment, as well as a lack of encouragement and concern among officials for female English teachers.

There were statistically significant differences in the obstacles facing female English teachers due to the their experience levels. This study suggests that the teachers with more experience are able to solve problems and can remove the obstacles and challenges that stand in the way of the educational process. There were no statistically significant differences in the obstacles facing female English teachers due to their age or qualifications, possibly because they face the same obstacles; and being older or more qualified does not necessarily mean they will have a better ability to face challenges and obstacles when teaching English.

\section{Conclusion}

The study investigated the obstacles facing female English secondary teachers in the Al-Qaser Directorate of Education in Al-Karak, Jordan. For this purpose, a questionnaire with 29 items covering five domains was distributed. The results of the study showed that many academic challenges and obstacles were faced by the teachers in the student and community/parent domains, as well as the teacher skills, curriculum, and school environment domains. The study results also show that there were statistically significant differences in the challenges and obstacles faced by female English language teachers due to their experience level. In light of these results, it is recommended that more effective strategies be adopted to improve the school environment and ensure the suitability of the psychological situation of female English teachers. It is also recommended that more training courses be conducted to improve teachers' ability to face the challenges and obstacles of the English language teaching process. It is also suggested that there is a need to conduct more research on the challenges faced by English language teachers. Finally, improvements should be made to the infrastructure in secondary schools in general, and in the Al-Qaser Directorate of Education, in particular, in terms of providing adequate classrooms and modern tools for teaching.

Since this study focused on the academic obstacles facing female English language teachers in Al-Karak, further research can be conducted to compare these results with those related to male teachers in order to determine whether both genders encounter the same challenges. Furthermore, studies that examine other types of obstacles such as behavioural ones can also be conducted to explore other areas of difficulties that need to be addressed. Finally, another study could make a comparison between the challenges faced by teachers in public and private schools. 


\section{Acknowledgments}

We wish to thank the four anonymous reviewers and the vice editor-in-chief of the Journal of Language and Education for their useful comments on an earlier draft of the paper. We would also like to thank the participants who took part in this study.

\section{Conflict of interests}

The authors declare that they have no conflict of interest.

\section{References}

Ahmad, M. (2003). Professional difficulties facing secondary school English language teachers and its effect in classroom performance in northern governorates of Palestine [Unpublished Master's thesis]. Al-najah National University.

Akasha, O. (2013). Exploring the challenges facing Arabic-speaking ESL students \& teachers in middle school. Journal of ELT and Applied Linguistics, 1(1), 12-31.

Al-Amarat, M. (2017). The classroom problems faced teachers at the public schools in Tafila Province, and proposed solutions. International Journal of Education Sciences, 3(1), 37-48. https://doi.org/10.1080/0975112 2.2011.11890007

Alkahtani, A. (2017). The challenges facing the integration of ICT in teaching in Saudi secondary schools. International Journal of Education and Development using ICT, 13(1), 32-51.

Alkhawaldeh, A. (2010). The challenges faced by Jordanian English language teachers at Amman 1st and 2nd directorates of education. College Student Journal, 44(4), 836.

Alzyat, F. (2014). Problems of teaching English language culture in Jordanian public schools [Unpublished Master's thesis]. Middle East University.

Awajan, N. (2010). Factors that enhance English language teachers' motivation in Jordanian secondary public schools [Unpublished Master's thesis]. Middle East University.

Borich, D., \& Tombari, L. (2004). Educational assessment for the elementary and middle school classroom ( $2^{\text {nd }}$ ed.). Pearson Education Inc.

Brown, A.V. (2009). Students' and teachers' perceptions of effective foreign language teaching: A comparison of ideals. The Modern Language Journal, 93(1), 46-60. https://doi.org/10.1111/j.1540-4781.2009.00827.x

Burden, P. (2020). Classroom management: Creating a successful K-12 learning community. John Wiley \& Sons.

Canagarajah, A. (2012). TESOL at forty: What are the issues? TESOL Quarterly, 40(1), 9-34. https://doi. org/10.2307/40264509

Çelik, S., Arikan, A., \& Caner, M. (2013). In the Eyes of Turkish EFL Learners: What makes an effective foreign language teacher? Online Submission, 20, 287-297.

Cho, S., \& Reich, G. (2008). New immigrants, new challenges: High school social studies teachers and English language learner instruction. The Social Studies, 99(6). https://doi.org/10.3200/TSSS.99.6.235-242

Clunies-Ross, P., Little, E., \& Kienhuis, M. (2008). Self-reported and actual use of proactive and reactive classroom management strategies and their relationship with teacher stress and student behaviour. Journal of Educational Psychology, 28(6), 693-710. https://doi.org/10.1080/01443410802206700

Deaeghere, J., Williams, R., \& Kyeyune, R. (2009). Ugandan secondary school head teachers' efficacy: What kind of training for whom. International Journal of Educational Development, 29(3), 312-320. https://doi. org/10.1016/j.ijedudev.2008.03.001

Dhillon, J., \& Wanjiru, J. (2013). Challenges and strategies for teachers and learners of English as a second language: The case of an urban primary school in Kenya. International Journal of English Linguistics, 3(2), 1424. http://dx.doi.org/10.5539/ijel.v3n2p14

Elyas, T., \& Al Grigri, W. (2014). Obstacles to teaching English in Saudi Arabia public schools: Teacher's and supervisor's perceptions. International Journal of English Language Teaching, 2(3), 74-89.

Filter, K., \& Horner, R. (2009). Function-based academic interventions for problem behaviour. Journal of 
Education and Treatment of Children, 32(1), 1-19.

Gardner, R. C. (2001). Integrative motivation: Past, present and future. http://publish.uwo.ca/gardner/docs/ GardnerPublicLecture1.pdf.

Hamasha, S. (2000). Administrative problems facing the newly appointed teachers in the first three grades in Irbid government schools [Unpublished master's thesis]. Yarmouk University.

Hararsh, M., \& Kawaldh, S. (2009). The patterns of control implemented by the classroom teachers in order to maintain disciplinant in the classroom in Al- Mafraq District of Education. Journal of Damask University, 25(1-2), 443-465.

Hazaymeh, W., \& Altakhaineh, A. R. M. (2019). The effect of flipped classroom instruction on developing Emirati EFL learners' pragmatic competence. International Journal of Learning, Teaching and Educational Research, 18(10), 89-111. https://doi.org/10.26803/ijlter.18.10.6

Hussain, S. (2001). Education in Pakistan. Allama Iqbal Open University.

Izadpanah, S. (2011). The review study: The place of culture in English language teaching. US-China Foreign Language, 9(2), 109-116.

Karatas, P., \& Karaman, C. (2013). Challenges faced by novice language teachers: Support, identity and pedagogy in the initial years of teaching. International Journal of Research in Teacher Education, 4(3), 10-23.

Khong, T., \& Saito, E. (2013). Challenges confronting teachers of English language learners. Educational Review, 66(2), 210-225. https://doi.org/10.1080/00131911.2013.769425

Kini, T., \& Podolsky, A. (2016). Does teaching experience increase teacher effectiveness? A review of the research. Learning Policy Institute.

Kocabas, I. (2009). The effects of sources of motivation on teachers' motivation levels. Education Journal, 129(4).

Momen, H. (2009). Language and multilingual in scientific communication. Singapore Medical Journal, 50(7), 654-656.

Paran, A. (2012). Language skills: Questions for teaching and learning. ELT Journal, 66(4), 450-458. https:// doi:10.1093/elt/ccs045

Saeed, M., Ahmad, I., Salam, M., Badshah, R., Ali, S., \& ul-Haq, S. (2013). Critical analysis of problems of school teachers in Pakistan: Challenges and possible solutions. Journal of Education and Practice, 4(4), 169-175.

Seals, C., Mehta, S., Berzina-Pitcher, I., \& Graves-Wolf, L. (2017). Enhancing teacher efficacy for urban STEM Teachers facing challenges to their teaching. Journal of Urban Learning, Teaching, and Research, 13, 135-146.

Sentance, S., \& Csizmadia, A. (2017). Computing in the curriculum: Challenges and strategies from a teacher's perspective. Education and Information Technologies, 22(2), 469-495. https://doi.org/10.1007/s10639-0169482-0

Tambwe, M. A. (2019). Challenges facing the implementation of a competency-based education and training (CBET) system in Tanzanian technical institutions. In J. Lugalla \& J. Ngwaru (Eds.), Education in Tanzania in the era of globalisation: Challenges and opportunities (pp. 242-255). Mkuki na Nyota. https://doi.org/10.2307/j. ctvh8r02h.24

Teevno, R. (2011). Challenges in teaching and learning of English at secondary level class X. International Journal of Human Resource Studies, 1(2), 27-35. https://doi.org/10.5296/ijhrs.v1i2.1029

Warsi, J. (2004). Conditions under which English is taught in Pakistan: An applied linguistic perspective. SARID Journal, 1(1), 1-9.

Zibin, A., \& Altakhaineh, A. R. M. (2019). The effect of blended learning on the development of clause combining as an aspect of the acquisition of written discourse by Jordanian learners of English as a foreign language. Journal of Computer Assisted Learning, 35(2), 256-267. https://doi.org/10.1111/jcal.12327. 